\title{
Labirinto da saúde no Brasil: a pandemia e o minotauro
}

| ${ }^{1}$ Catalina Kiss, ${ }^{2}$ Leandro A. P. Gonçalves I

1 Programa de Pós-Graduação em Saúde da Família, Universidade Estácio de Sá. Rio de Janeiro-RJ, Brasil (catalinakiss9@gmail.com).
ORCID: 0000-0001-6298-8681
${ }^{2}$ Instituto de Saúde Coletiva, Universidade Federal Fluminense. Rio de Janeiro-RJ, Brasil (goncalves.lap@gmail). ORCID: 0000-0002-6795-8374
Recebido em: 05/06/2020
Aprovado em: 18/06/2020
Revisado em: 22/06/2020

DOI: http://dx.doi.org/10.1590/S0103-73312020300305

Início de junho de 2020: o Brasil disputa com os Estados Unidos a liderança em número de novos casos e mortes diárias pela Covid-19. De maneira crescente, a epidemia não nos dá fôlego e parece longe de alcançar o táo esperado - uma esperança estranha - "pico". Apesar de a tragédia estar ainda longe de um termo, sequer próxima de um entendimento e enfrentamento coerentes, já há quem esteja comemorando alguns números, como o esvaziamento dos leitos dos hospitais privados em algumas capitais. Guilherme Benchimol - um desses especuladores financeiros tấo frequentes no Governo Federal, que lideram, inclusive, o Ministério da Educaçáo - chegou a dizer que o "pico" nas classes médias e altas já havia passado, o que indicava que o Brasil estava bem. "O desafio é que o Brasil tem muita comunidade, muita favela", disse Guilherme, fundador e presidente da empresa de investimentos XP, ainda no início de maio (MOURA, 2020).

No Estado do Rio de Janeiro, cerca 300 pessoas aguardam um leito hospitalar. Havia a expectativa e a promessa de que o governo do Estado entregasse nove hospitais de campanha, que poderiam absorver parte do "pico" epidêmico até o final de abril (EXTRA RIO, 2020). No momento em que escrevemos este texto, o Rio de Janeiro é o segundo em número de casos e mortes em toda a federação, e o Brasil caminha 
para ser o epicentro da pandemia no mundo. Bem próximo da capital do estado, no segundo município mais populoso da regiáo metropolitana - São Gonçalo -, a inauguração de um desses hospitais de campanha foi adiada quatro vezes; a última delas justificada pela invasão contaminante das obras de um deputado estadual, Filippe Poubel, da base política de Jair Bolsonaro, com simpatizantes armados. No quarto município mais populoso da regiáo metropolitana, Nova Iguaçu, foram cinco inaugurações adiadas.

A organização social Instituto de Atenção Básica e Avançada à Saúde (IABAS), responsável pela obra e gestão de sete dos nove hospitais de campanha, inclusive pelos seis que não foram entregues, justifica o atraso pois o Tribunal de Contas do Estado bloqueou os pagamentos feitos pela Secretaria de Estado de Saúde (SES-RJ) ao IABAS, que seriam da ordem de 700 milhóes, por conta de supostas irregularidades (EXTRA RIO, 2020). Outros dois hospitais, curiosamente nos privilegiados bairros cariocas do Leblon e da Barra, já estáo funcionando a pleno vapor, construídos e geridos por um grupo de entidades privadas liderado pela Rede D'or. Entre algumas das saídas para o impasse relativo ao IABAS, uma passa a ser a entrega de todas as unidades de campanha para um consórcio de entidades privadas, como se fossem as únicas estruturas capazes de dar conta da grave situação sanitária e de gestão (TOLEDO; LISBOA, 2020).

Sobre a problemática da entrega da execução de açôes sanitárias públicas e emergenciais ao setor privado, há nuances muito preocupantes. Em São Paulo, a força de trabalho tem sido empregada no enfrentamento à Covid-19 através de contratos precaríssimos, quando os há. O IABAS, que é um dos gestores do hospital de campanha do Anhembi, contrata profissionais de saúde através de uma empresa quarteirizada, que oferece contratos na categoria "trabalhador intermitente", cuja forma não garante qualquer benefício em caso de adoecimento pelo coronavírus (SARS-CoV-2). Na cidade de São Paulo, há dois hospitais de campanha cujos trabalhadores são vinculados através de quarteirizadas, via contratos de Pessoa Jurídica, cooperativas e até por pagamento direto sem contrato. Um dos hospitais, o do Pacaembu, é gerido pelo Hospital Israelita Albert Einstein; o outro, no Anhembi, é gerido pelo IABAS e pela Associação Paulista para o Desenvolvimento da Medicina (SPDM). Todas as instituiçôes acima, quando questionadas sobre o desamparo contratual a que estão submetidos os trabalhadores que cotidianamente são expostos à contaminação pelo coronavírus, dizem estar em acordo com a lei 
vigente; o Albert Einstein, inclusive, afirmou disponibilizar sua rede de clínicas para que os trabalhadores pudessem se cuidar (AMÂNCIO, 2020).

Além do desamparo, os trabalhadores da saúde estão em pânico. Em pesquisa recentemente divulgada pela Fundação Getúlio Vargas, trabalhadores da saúde de todo o território nacional revelam o medo cotidiano ao lidar com o avanço da epidemia. Sentem-se despreparados, desprotegidos; quanto mais abaixo na perversa hierarquia profissional da saúde estão, maior a sensação. $\mathrm{Na}$ pesquisa, 91,3\% dos agentes comunitários de saúde que participaram dela se dizem apavorados. Um enfermeiro disse:

Estou tendo que adquirir meu próprio material [de proteção] e o da minha família. Minha esposa também trabalha em hospital e precisa usar, pois tem comorbidades. Se nâo fosse eu mesmo ir buscar informaçóes sobre como atuar e estudar sobre o vírus, principalmente em canais internacionais, eu e minha família estaríamos 100\% perdidos (BERTONI, 2020).

$\mathrm{Na}$ conjuntura aguda do avanço da epidemia pelo SARS-CoV-2 no Brasil, as pessoas que precisam de cuidados médicos estão desamparadas por um sistema de saúde historicamente fragilizado; os profissionais de saúde estáo contratual e tecnicamente desamparados; até mesmo os gestores da saúde, algo mais próximo a uma autoridade sanitária a que se possa recorrer, parecem amarrados aos contratos com prestadores de serviços privados. Uma pergunta simples: há algo ou alguém que possa se responsabilizar por tamanho desamparo? Resposta cruel: procure no labirinto...

\section{Avisos para encarar o labirinto}

O SUS nasceu a contrapelo: a partir da $8^{a}$ Conferência Nacional de Saúde e da organização da Comissão Nacional da Reforma Sanitária, o Movimento pela Reforma Sanitária Brasileira (MRSB) buscou assegurar uma proposta para o setor na Carta Constitucional de 1988. Na contramáo dos desafios da consagrada "década perdida", a saúde passou a ser um direito assegurado pelo Estado a todos os habitantes do território nacional, sem qualquer distinçâo. Entre os dilemas internos do setor no período, a implantação de distritos sanitários, a transferência do Inamps para o Ministério da Saúde e a relação com o setor privado eram as pautas prioritárias para o desenho do novo sistema nacional de saúde. Acontece que o Consenso de Washington ${ }^{1}$ estava para acontecer em 1989, assim como a vitória do liberal conservador Fernando Collor de Mello, que assumiu o poder em 1990. As leis que 
fundam o SUS são formuladas e publicadas, com vetos, sob a sua presidência. Além da conjuntura favorável ao avanço liberal, o MRSB apostou que poderia submeter o setor privado aos interesses de uma política nacional. Estava posto um importante dilema para o SUS: como servir a dois senhores?

O processo de descentralização a golpes de portaria: a Constituição colocou alguns problemas importantes para se construir um novo sistema de saúde. $\mathrm{O}$ principal deles: a transformação dos municípios em entes federados e a gestão tripartite do SUS, com a indicação de que os municípios deveriam ser os principais responsáveis pela execução das açôes sanitárias. Acontece que boa parte do arcabouço dos serviços de saúde instituídos eram federais e estaduais. Foi preciso repassar essas estruturas, inclusive toda a força de trabalho aos municípios e fomentar a consolidação das redes locais de atenção à saúde. A descentralização foi feita "a golpes de portaria” (GOULART, 2001), via repasses financeiros, o que manteve a União com o controle do leme através do Ministério da Saúde (MACHADO; BAPTISTA; LIMA, 2015). Por meio da expansão da Atenção Primária à Saúde, da implantação do modelo Saúde da Família, o Brasil esbarrou nos limites político-administrativos dos entes federados, que de tão desiguais e incipientes, dificultaram a consolidação das redes locais de atenção à saúde. Ou seja, estâo dados os limites para a garantia da integralidade à saúde dos cidadãos. Isto só foi efetivamente enfrentado no tardio ano de 2011, através do Decreto no 7.508. Tarde demais?

Os recursos nunca foram escassos. Eles foram escasseados: A noção de Seguridade Social, talvez a marca mais ousada da Constituição de 88, nem nasceu. Virou nome de Instituto - Instituto Nacional do Seguro Social (INSS); este, por sinal, pouco se deslocou da sua tradicional lógica previdenciária. A solidariedade tão almejada entre a saúde, previdência social e assistência social foi estrangulada desde o princípio pelo sequestro de seus recursos. O financiamento do nascente SUS, que viria dessa fonte, nunca foi regulamentado. Na verdade, o financiamento que veio a ser definido em 2011 pela Emenda Constitucional (EC) 29 mal foi regulamentado e já está congelado por 20 anos através da EC 95 de 2016, a "PEC da Morte" (PINTO, 2017). Até 2011, o SUS precisou de penduricalhos normativos para não fenecer, e a expressão de "pires nas mãos" (NETO, 1995) ficou conhecida na Saúde. As emendas parlamentares como estratégia de financiamento produziram caminhos tortuosos entre a negociação político-eleitoral e a aplicação de recursos financeiros, tornando-se praticamente a única fonte de novos investimentos no SUS (BAPTISTA 
et al., 2012). Enquanto isso, o Estado intensificava a entrega de fatias dos recursos da Seguridade Social diante das pressóes de organismos internacionais, criando geringonças normativas como a Desvinculação de Receitas da União. Para piorar, travestido de benesse para a classe média, o Estado seguiu financiando a adesão de pessoas e os próprios seguros privados de saúde através de vultosas renúncias fiscais...

Na impossibilidade de planejamento, transforme o Estado em "commodities" e entregue à iniciativa privada: Não obstante o aspecto organizativo difuso do sistema de saúde, com suas estruturas superpostas e pouco articuladas entre os três entes federados, ainda foram criadas as agências reguladoras para fiscalizar os setores produtivos e entregou-se a execução das açôes de diferentes estruturas do SUS ao setor privado. $\mathrm{Na}$ "onda do MARE - Ministério da Administração e Reforma do Estado”, fruto do Consenso de Washington, tais agências, as organizaçōes sociais e as fundaçóes estatais de direito privado vieram com o propósito de promover independência e autonomia em relação à União e à negociação política (FIER, 1996). Nem independentes, nem autônomas, as redes locais de atenção à saúde perderam transparência na execução de suas ações e a possibilidade de participação social, fragilizando princípios e diretrizes do sistema de saúde. O problema que era político e financeiro também se tornou administrativo, e a onda do MARE, por fim, nos afogou. A partir dos anos 2000, a administraçáo direta do Estado foi sumindo... e como não há vácuo, instituições de direito privado tomaram seu lugar e seus recursos.

Os tentáculos do setor privado: você tem fome de quê? Muito longe da noção liberal de competição saudável do mercado, de seus valores de qualidade, resolutividade e efetividade, o setor saúde foi entregue à lógica especulativa e extrativa do setor privado. $\mathrm{O}$ acesso à saúde no Brasil está refém dessa lógica. $\mathrm{O}$ setor privado, coerente com seus pressupostos, avança em domínios de alto retorno de capital; em passos largos; coloca-se como a única fonte de oferta de serviços ao sistema público. Neste processo de entrega e controle da máquina pública, não existe auditoria e sistema de regulação que dê conta de garantir os princípios e diretrizes do SUS. Entram novos atores, do Ministério Público às clínicas populares, e reforçam que o distanciamento da administração direta da execução da saúde nos seus diversos níveis veio para ficar e fortalecer o mercado de prestação de serviços. A cada ciclo eleitoreiro, uma "rede de apoio" prolifera em torno do sistema, nos mais diversos aspectos logísticos e fisiológicos, boicotando a implantação de um sistema integrado de informação e 
o exercício da vigilância à saúde, ficando o SUS à sorte da especulação. "Quem dá mais?". A pandemia da Covid-19 tem deixado tudo à vista de todos.

Dentro do labirinto, estamos face a face com o minotauro.

\section{Seguindo o fio de Ariadne, buscando a saída...}

O que temos em comum? Debates de caráter ético desapareceram do nosso cotidiano. Eles costumam ser interditados por falas como "essa discussão não nos levará a lugar nenhum”, "precisamos ser pragmáticos", "desculpem, acho que viajei” e outras mais. Acontece que no fundo dessa interdição do debate em torno de valores estão valores e pactos éticos muito bem definidos e compartilhados por todos como se fosse uma segunda natureza nossa: a propriedade privada, a noção de indivíduo, a acumulação e a competição irmanada com o mérito. Ora, esta é a ética liberal. Ela foi "universalizada" pela mundialização dos Estados-nação, o avanço do capitalismo industrial, a expansão dos mercados autorregulados - os "moinhos satânicos" - e das instituiçôes multilaterais "globais", como nos mostrou Karl Polanyi (2000). O minotauro que encontramos aqui é uma criatura desse processo. Para iniciarmos a trajetória de saída do labirinto, é preciso enfrentar a criatura e seguirmos o fio que nos deu Ariadne de volta. Encararmos o debate ético, da forma mais ampliada possível, e não apenas nas esferas acadêmicas e das ciências humanas, é como tomar nas mãos a ponta desse fio. Esse debate é um movimento importante para colocar visível o liberalismo que nos atravessa e começarmos a nos livrar dele, preparando o caminho para colocar algo no seu lugar. Este algo precisa passar pelo comum, pela garantia da diferença, pela solidariedade e pela noção de que as vidas importam, todas elas, não apenas as humanas.

Pela sustentaçáo do direito público e da administraçáo pública. Seguindo o fio, o debate ético nos leva a lidar com a problemática do direito de cada um, de todos e da administração daquilo que temos em comum. Hoje estamos reféns do direito privado e da administração privada como garantia daquilo que nos é comum. O direito público e a administração pública são tidas como ineptas, ultrapassadas, inflexíveis, impossíveis. É raro encontrar no debate público quem mande a real: no Brasil, o direito e a administração pública como os temos hoje foram forjados na década de 1960 e 1970, ou seja, por um regime autoritário, privatista e antissolidário, como nos apontou Paulo Arantes (2010). Nosso direito comum e a administração do que nos é comum são condicionadas por essa formulação e formam o anteparo para 
o reinado do que é privado e individual nos dias de hoje. Portanto, o caminho aberto pelo debate ético nos provoca novas formulaçôes sobre questôes que já mobilizaram as pessoas que fazem parte do MRSB em outros tempos, mas que foram interditados também. São elas: a esfera estatal, a esfera pública, a esfera privada e suas interseções. O direito público e a administração pública podem e devem ser repactuados e se tornarem possíveis em nosso tempo.

Por um novo pacto federativo. O papel protetor e o poder redistributivo de uma instituição organizadora central, que temos chamado de Estado, está sendo resgatado a fórceps pela pandemia da Covid-19 e pelas aberraçóes das novas regras do jogo postas no tabuleiro geopolítico "global" (FIORI, 2018). Aqui, "o muro do vizinho" e a limitada autonomia de governabilidade sobre a crise se puseram entre os diferentes entes. No Brasil, parece impossível escaparmos, no tempo próximo, da revisão do seu pacto federativo como forma de desarmar os diversos arranjos políticos e a perpetuação das desigualdades sociais; estas fortalecem o mau uso dos recursos públicos e configuram o jogo institucional cíclico do "toma-lá-dá-cá". A crise do federalismo brasileiro não atinge somente os limites da conformação das redes de atenção à saúde; o "cada um por si” expresso nessa pandemia esteve presente ao longo de décadas de tentativas de ações intersetoriais. Conforme dados divulgados pelo IBGE (2019), o país ostenta 5.570 municípios, sendo que metade da população brasileira reside em apenas 324 municípios (5,8\%); em 3.670 municípios habitam, em cada um deles, até 20.000 brasileiros. A intenção municipalista que almejou a descentralização durante a transição democrática como forma de um resguardo popular da tirania central, teve que se ver com a competiçáo deletéria posta em curso nas tortuosas guerras fiscais entre os estados, regulamentaçóes fratricidas e a virada fiscal ocorrida na década de 1990 (RIBEIRO; MOREIRA, 2016). Sobre a questão fiscal e tributária nacional, é estarrecedor seu caráter regressivo, penalizando pessoas e territórios vulnerabilizados. Para enfrentar desigualdades, precisamos de pactos e instituiçôes que redistribuam recursos, que enfrentem o espólio e a vulnerabilização da maioria. "Que país é este"2 que queremos?

Estado e sociedade civil: cabe separar? A semântica das Ciências Sociais, sobretudo da Ciência Política, nos leva a uma leitura analítica da nossa organização social, pondo e reificando o Estado como um ente e a sociedade civil como outro. Ora, sabemos bem que instituiçôes são feitas por pessoas, através dos seus pactos, e que qualquer separação é artificial. Pessoas que vivem em comum precisam se 
organizar e produzem suas instituições. Essas instituiçôes podem se chamar Estado, podem se chamar quilombo, podem se chamar soviete, podem se chamar sociedade anônima e por aí vai... todas são instituições sustentadas por valores em comum. Portanto, para encerrar, o fio enovelado de Ariadne nos faz reaproximar do começo para então prepararmos a saída do labirinto: precisamos de um novo pacto ético para termos outra política e outras instituiçóes que nos garantam viver e gozar nossas potencialidades pessoais; estas só podem ser garantidas coletivamente.

Hoje temos as instituiçóes militares brasileiras preparando sua revanche contra quem buscou enfrentar as desigualdades que se reproduzem e se intensificam no território brasileiro. Mesmo a classe média volta a ter o sono atravessado com a possibilidade de perder suas "liberdades civis". Um alerta: nenhum "direito civil" está garantido enquanto pessoas negras e indígenas morrem nas nossas "periferias", seja por tiros, seja pelo coronavírus. Precisamos de instituiçôes que potencializem os víveres; facas em caveiras, arminhas com a mão, caveirão blindado e voador, "general de 10 estrelas que fica atrás da mesa com o cu na mão"3 precisam se tornar peças de museu para lembrarmos um dia o que não podemos nunca mais voltar a ser. Saúde é poder viver e é poder lembrar.

\section{Referências}

AMÂNCIO, T. Hospitais montados para Covid-19 não dão garantias caso trabalhador adoeça. PortalFOLHA, 2020. Disponívelem:https://wwwl.folha.uol.com.br/equilibrioesaude/2020/04/ hospitais-montados-para-covid-19-nao-dao-garantias-caso-trabalhador-adoeca.shtml. Acesso em: 5 jun 2020.

ARANTES, P. E. 1964, o ano que não terminou. In: TELES, E.; SAFATLE, V. (Orgs.). O que resta da ditadura: a exceção brasileira. São Paulo: Boitempo, 2010. p. 205-236.

BAPTISTA, T. W. F. et al. As emendas parlamentares no orçamento federal da saúde. Cad. Saúde Pública, Rio de Janeiro, v. 28, n. 12, p. 2267-2279, dez. 2012.

BERTONI, E. Os relatos de medo e abandono de profissionais de saúde. Portal NEXO, 2020. Disponível em: https://www.nexojornal.com.br/expresso/2020/05/28/Os-relatosde-medo-e-abandono-de-profissionais-de-sa\%C3\%BAde?utm_medium=Email\&utm _ campaign=BoletimCoronavirus\&utm_source=datawall. Acesso em: 5 jun. 2020.

EXTRA RIO. Onde o Rio falhou no combate ao coronavírus. Portal EXTRA, 2020. Disponível em: https:/extra.globo.com/noticias/rio/onde-rio-falhou-no-combate-aocoronavirus-24452336.html. Acesso em: 5 jun. 2020. 
FIER, F. O SUS e as Organizações Sociais. Saúde em Debate, n. 52, p. 83-89, set. 1996.

FIORI, J. L. Geopolítica internacional: a nova estratégia imperial dos Estados Unidos. Saúde em Debate. Rio de Janeiro, v. 42, n. esp. 3, p. 10-17, nov. 2018.

GOULART, F. A. A. Esculpindo o SUS a golpes de portaria... - consideraçóes sobre o processo de formulação das NOBs. Ciênc. saúde coletiva, v. 6, n. 2, 2001.

INSTITUTO BRASILEIRO DE GEOGRAFIA E ESTATÍSTICA. IBGE divulga as estimativas da populaçãodos municípiospara 2019. PortalIBGE, 2019. Disponívelem: https://agenciadenoticias. ibge.gov.br/agencia-sala-de-imprensa/2013-agencia-de-noticias/releases/25278-ibge-divulgaas-estimativas-da-populacao-dos-municipios-para-2019\#:-:text=IBGE\%20divulga\%20as\%20 estimativas\%20da\%20popula\%C3\%A7\%C3\%A3o\%20dos\%20munic\%C3\%ADpios\%20 para\%202019,-Editoria\%3A\%20Estat\%C3\%ADsticas\%20Sociais\&text=O\%20IBGE\%20 divulga\%20hoje\%20as,1\%C2\%BA\%20de\%20julho\%20de\%202019. Acesso em:5 jun. 2020.

MACHADO, C. V.; BAPTISTA, T. W. F; LIMA, L. D. Politicas de saúde no Brasil: continuidades e mudanças. Rio de Janeiro: Editora Fiocruz, 2015.

MOURA, J. Pico de Covid-19 nas classes altas já passou; o desafio é que o Brasil tem muita favela, diz presidente da XP. Portal FOLHA, 2020. Disponível em: https://www1.folha.uol.com. br/mercado/2020/05/brasil-esta-indo-bem-no-controle-do-coronavirus-e-pico-nas-classesaltas-ja-passou-diz-presidente-da-xp.shtml. Acesso em: 5 jun. 2020.

NETO, E. R. SUS: quem são os verdadeiros vilóes. Saúde em Debate, n. 49-50, dez 95 / mar 96.

PINTO, E. G. Financiamento dos direitos à saúde e à educação: uma perspectiva constitucional. Belo Horizonte: Fórum, 2017.

POLANYI, K. A grande transformação: as origens de nossa época. 2. ed. Rio de Janeiro: Campus, 2000.

RIBEIRO, J. M.; MOREIRA, M. R. A crise do federalismo cooperativo nas políticas de saúde no Brasil. Saúde em Debate. Rio de Janeiro, v. 40, n. esp., p. 14-24, dez. 2016.

TOLEDO, M.; LISBOA, V. Rio quer que iniciativa privada administre hospitais de campanha. Portal AGENCIA BRASIL, 2020. Disponível em: https://agenciabrasil.ebc.com.br/saude/ noticia/2020-05/rio-quer-que-iniciativa-privada-administre-hospitais-de-campanha. Acesso em: 5 jun. 2020.

\section{Notas}

${ }^{1}$ Sobre este assunto, recomendamos a palestra proferida por José Luis Fiori, "O consenso de Washington", disponível em: <https://www.youtube.com/watch?v=LN783p7xdsk>.

${ }^{2}$ Menção à música "Que país é este?", da banda Legião Urbana.

${ }^{3}$ Menção à música "Faroeste Caboclo", da banda Legião Urbana. 